\title{
ПРОБЛЕМЫ ПЕРВОНАЧАЛЬНОГО ЭТАПА РАССЛЕДОВАНИЯ НАСИЛЬСТВЕННЫХ ПЕНИТЕНЦИАРНЫХ ПРЕСТУПЛЕНИЙ
}

\author{
В. С. Ишигеев ${ }^{1}$, О. П. Грибунов ${ }^{2}$ \\ 1 Байкальский государственный университет, г. Иркутск, Российская Федерация \\ ${ }^{2}$ Восточно-Сибирский институт Министерства внутренних дел Российской Федерации, г. Иркутск, \\ Российская Федерация
}

\section{Информация о статье}

Дата поступления

29 сентября 2017 г.

Дата принятия к печати 20 ноября 2017 г.

Дата онлайн-размещения 27 ноября 2017 г.

\section{Ключевые слова}

Расследование; насильственные преступления; места лишения свободы; следственные действия

\begin{abstract}
Аннотация
В статье рассматриваются некоторые криминалистические аспекты выявления и расследования насильственных преступлений в местах лишения свободы, а также тактические проблемы, возникающие на этапе предварительного следствия. Проанализированы основные аспекты первоначального этапа расследования насильственной преступности в исправительных учреждениях. Определены условия эфффективного осуществления первоначального этапа расследования преступлений указанной категории, среди которых важное значение имеет установление точного места нахождения преступника и возможность своевременного изолирования свидетелей с целью сохранения тайны следствия, обеспечения безопасности участников. Рассмотрена роль взаимодействия следователя с органом дознания, а также психологическими службами колонии, которые отслеживают состояние осужденных и могут прогнозировать поведение некоторых участников преступного события. Определена особая специфика расследования насильственных преступлений в местах лишения свободы и значимость реализации различных аспектов частной криминалистической методики данного вида преступных деяний.
\end{abstract}

\section{PROBLEMS OF THE INITIAL STAGE OF INVESTIGATION OF VIOLENT PENITENTIARY CRIMES}

\author{
Vladimir S. Ishigeev ${ }^{1}$, Oleg P. Gribunov ${ }^{2}$ \\ ${ }^{1}$ Baikal State University, Irkutsk, Russian Federation \\ ${ }^{2}$ East-Siberian Institute of the Ministry of the Interior of Russia, Irkutsk, Russian Federation
}

Article info

Received

September 29, 2017

Accepted

November 20, 2017

Available online

November 27, 2017

\section{Keywords}

Investigation; violent crimes; places of confinement; investigative activities

\begin{abstract}
This article examines some forensic aspects of the detection and investigation of violent crimes in places of confinement as well as the main tactical problems of the initial stage of the investigation. Conditions of effective implementation of the initial stage of the investigation of crimes of this category are determined, among which the important role belongs to the determination of the exact location of the offender and the possibility of timely isolation of witnesses. That is vital to preserve the secrecy of the investigation, and to ensure the safety of participants. The authors examine the role of interaction of the investigator with the body of inquiry and with psychological services of the penal establishment that trace a condition of convicts and can predict behavior of some participants of a criminal event. They define the specificity of investigation of violent crimes in places of detention and the importance of implementation of various aspects of a special criminalistic technique of this type of criminal acts.
\end{abstract}


Уровень пенитенциарной насильственной преступности считается одним из наиболее важных показателей эффективности противодействия преступности в местах лишения свободы. В соответствии с положением "О Федеральной службе исполнения наказаний», утвержденным указом Президента РФ от 13 октября 2004 г. № 1314, среди прочих приоритетной задачей ФСИН России является обеспечение охраны прав, свобод, законных интересов осужденных, а также обеспечение правопорядка и законности в исправительных учреждениях (ИУ). Выполнить указанную задачу в условиях повсеместно распространенного на территориях колоний России насилия невозможно.

Кроме того, криминальное поведение осужденных опасно не только причинением непосредственного фризического вреда потерпевшему, но и лишением возможности исправительного воздействия. Анализ статистических данных ГИАЦ МВД России за 2012-2016 гг. свидетельствует о стабильно низком уровне пенитенциарных насильственных преступлений в общей структуре преступности (около 0,3 \%, т. е. не более 150 преступлений в год), однако официальная статистика не учитывает уровень латентности рассматриваемых преступлений, что объясняется рядом специфических факторов, включая наличие криминальной субкультуры, режим отбывания наказания и др. Учитывая общую напряженную ситуацию в стране, экономический и политический дисбаланс, можно смело предположить, что криминальный мир незамедлительно отреагирует на происходящее в современной России новой волной насилия, в том числе и в местах лишения свободы [1, с. 3-7].

Таким образом, деятельность следователя на первоначальном этапе расследования насильственных преступлений в условиях ИУ осложняется рядом объективных обстоятельств, в связи с чем немаловажная роль отводится поиску эффрективных методов расследования и выявления указанных преступлений с обязательным использованием рекомендаций криминалистической систематики [2, с. 3] и криминалистической тактики [3]. Все это свидетельствует о необходимости формирования криминалистических методик раскрытия, расследования и предупреждения пенитенциарных преступлений против личности, которые, по справедливому утверждению А. В. Варданяна и Р. В. Кулешова, способствуют «повышению эфрфективности расследования различных видов и групп преступлений» $[4$, с. 8$]$.
Происходящие в ИУ негативные процессы в определенной степени противодействуют провозглашенным в Уголовно-исполнительном кодексе РФ целям наказания. Кроме того, в колониях России продолжается ухудшение контингента в основном из-за оттока положительно характеризующихся осужденных и увеличения числа осужденных, отбывающих наказание за тяжкие и особо тяжкие преступления [5, с. 29]. Пребывание таких осужденных в ИУ обусловливает существование благоприятного для совершения насильственных преступлений микроклимата [6, с. 5] с вероятностью заражения впервые осужденных идеями криминальной субкультуры.

Латентный характер насильственных пенитенциарных преступлений - побоев, истязаний, насильственного мужеложства, в значительной мере ставших как бы нормой тюремно-лагерного мира, с одной стороны, объясняется как спецификой взаимоотношений осужденных друг с другом (наличие криминального управления и суда, жесткая иерархичность в стратах и т. д.) [7, с. 17], так и нарушением прав осужденных персоналом колоний. Надо признать, что недоносительство - это элемент субкультуры тюремного мира.

Например, является традиционным мнение о низкой латентности убийств и умышленных причинений тяжкого вреда здоровью, основанное на выводе: чем серьезнее преступление, тем ниже его латентность. Однако данный факт не распространяется на тяжкие насильственные преступления, совершаемые в местах лишения свободы, поскольку определенное количество убийств, совершенных в ИУ, часто маскируется под самоубийства или несчастные случаи. В доказательственной базе обстоятельства совершения преступления искажаются, а убийство квалифрицируется как причинение тяжкого вреда здоровью, повлекшее смерть потерпевшего. На первоначальном этапе расследования преступных деяний в местах лишения свободы не исключена возможность фальсификации медицинских документов, а также игнорирования выводов экспертов.

Причинение вреда здоровью, даже тяжкого, зачастую выдается за производственные травмы. Издевательства, побои, насильственные акты мужеложства настолько привычное явление в ИУ, что в качестве преступлений они также игнорируются. Насилие, по признанию самих осужденных, стало нормой тюремной жизни, атрибутом взаимоотношений в местах лишения свободы с негласного одобрения как работников ад- 
министрации пенитенциарных учреждений, так и общества в целом [8, с. 43].

В качестве основных проблем первоначального этапа расследования насильственной преступности в ИУ следует назвать:

- нежелание осужденных сотрудничать и оказывать помощь в расследовании, так как они живут по канонам и обычаям криминального мира, прямо запрещающим какое-либо общение с представителями закона;

- борьба ИУ за статистические показатели эфффективности их деятельности, поскольку одним из показателей работы учреждений уголовно-исполнительной системы является исправление осужденных и недопущение совершения ими преступлений, что косвенно способствует укрытию от учета некоторых насильственных деяний от контролирующих органов (прокуратуры) с целью избежать дисциплинарных наказаний со стороны администрации ИУ;

- некачественное проведение осмотра места происшествия, приводящее прежде всего к потере следовой информации и искажению действительности;

- существование воровского закона, само по себе противодействующего расследованию на первоначальном и последующих этапах;

- недостаточная квалификация следователей, не обладающих специальными знаниями о специфике работы в местах лишения свободы, не желающих прибегать к помощи специалистов на первоначальном этапе расследования, в связи с чем видится уместным создание специализированных подразделений ФСИН, в чьи полномочия входило бы производство хотя бы дознания по уголовным делам в ИУ;

- боязнь угроз со стороны преступника, неуверенность в неизбежности его наказания, что влияет на показания потерпевших осужденных;

- дефекты правосознания и девиантное поведение большинства участников насильственных преступлений в ИУ (как преступников, так и потерпевших), связанные с нарушением психики и умственного развития.

Перечисленные детерминанты противодействия расследованию на первоначальном этапе лишь часть реального перечня проблем, с которыми приходится сталкиваться на практике.

Первоначальный этап расследования насильственных преступлений в ИУ требует от следователя максимальной оперативности действий, а также имеет ряд особенностей. Так, осмотр места происшествия включает в себя осмотр не только места совершения преступления, но и осмотр прилегающего участка местности - промзон и объектов, бытовых помещений, мест отдыха и досуга осужденных. Например, при расследовании убийства в колонии труп может быть перемещен с места реального совершения преступления.

Не стоит забывать и о положительных моментах, связанных с местом производства расследования. Так, все колонии оборудованы камерами видеонаблюдения, что позволяет изъять видеозапись и выяснить точное перемещение участников преступления. Однако осужденные находят места в колонии, не охваченные камерами наблюдения, и совершают насильственные действия именно там. При этом, зная хотя бы потерпевшего, можно дедукционно определить остальных участников преступления, отследив перемещение осужденных до или после его совершения. Еще одним достоинством расследования в ИУ является точное определение места нахождения преступника, возможность быстро и в любой момент доставить всех участников деяния к следователю, а также своевременно изолировать некоторых свидетелей с целью сохранения тайны следствия или обеспечения безопасности участников. Однако по неписаным законам тюремного мира информация ○ преступлении распространяется быстрее, чем начинается официальное расследование, что негативно влияет на следственную ситуацию на первоначальном этапе.

Еще одним бонусом пенитенциарного расследования можно назвать очевидность при установлении мотива преступления, поскольку все осужденные в колонии, как правило, знакомы между собой, а отношения «преступник - жертва» характеризуются допреступными конфликтными ситуациями, о которых известно на территории ИУ. Конфрликт между участниками преступления может быть обусловлен разнообразными детерминантами и иметь долгосрочный характер, что тоже необходимо выяснить при расследовании преступления. Как правило, остальные осужденные в колонии также знают о подробностях конфликта, но содействовать следствию не будут. Нередко действия преступника связаны с виктимообразующим поведением потерпевшего (прилюдные издевательства, в том числе насильственные действия сексуального характера), а значит, имеет место версия о самообороне или состоянии аффекта подозреваемого.

Здесь важную роль в расследовании играет процесс взаимодействия следователя с органом дознания ИУ, а также психологиче- 
скими службами колонии, которые отслеживают состояние осужденных и могут прогнозировать поведение некоторых участников преступного события. В связи с этим необходимо создавать специальные следственно-оперативные группы при производстве предварительного следствия в случаях, когда преступление повлекло появление большого числа свидетелей, потерпевших, соучастников, а значит, требуется больше затрат сил и средств при выполнении большего объема работ. Организация и деятельность указанных групп позволят обеспечить соблюдение одного из критериев допустимости доказательств о их сборе только уполномоченными лицами, а также помогут эфффективной работе в условиях дефицита времени.

Вообще, при расследовании не стоит пренебрегать знаниями сведущих лиц о субкультуре тюремного мира. К примеру, в случае обнаружения трупа следует установить характер повреждений и их взаимосвязь с обычаями преступного мира (традиционными наказаниями за проступок убитого - вырывание языка, обезображивание лица и др.). Так, переломы конечностей или следы сексуального насилия свидетельствуют об определенном смысле убийства как способа осуществления «тюремного приговора» по отношению к потерпевшему. Таким образом, источником подобных знаний могут быть как сотрудники администрации пенитенциарного учреждения, так и сами осужденные, разбирающиеся в обычаях и традициях преступного мира.

Для разъяснения отдельных вопросов, требующих знания так называемого воровского закона (значения татуировок, специальной лексики и т. д.), целесообразно прибегать к специальным знаниям не только при назначении и производстве судебных экспертиз, но и в ходе проведения допросов и других следственных действий.

Специфика расследования преступлений в местах лишения свободы на первоначальном этапе требует немедленного установления и допроса очевидцев насильственного деяния, так как промедление несет риск оказания на них в колонии отрицательного влияния с целью изменить информацию. Только своевременный допрос свидетелей является залогом установления объективной истины по делу.

Поскольку преступник, который совершил насильственное преступление в ИУ, полагает, что уличить его в содеянном невозможно, так как сотрудничество с представителями правоохранительных органов по тюремным обычаям запрещено, а значит, свидетели будут искажать реальные фракты события преступления, во время задержания и на первых допросах он не дает правдивых показаний, а зачастую отказывается от их дачи в порядке ст. 51 Конституции РФ. И именно предъявление ему правдивых показаний других осужденных может пошатнуть его уверенность в собственной безнаказанности.

Лицо, замаскировавшее убийство под несчастный случай, обычно пытается и на допросе объяснить смерть потерпевшего роковым стечением обстоятельств. Однако несоответствие его показаний фактическим обстоятельствам может быть использовано для установления истины. Здесь уместно произвести очную ставку или проверку показаний на месте для устранения противоречий.

При расследовании насильственных преступлений в местах лишения свободы проверка показаний на месте также имеет свою специфику. Ее проведение не должно нарушать режим отбывания наказания. В связи с этим во время планирования данного следственного действия необходимо принять повышенные меры безопасности с учетом правил распорядка дня в колонии.

Таким образом, можно отметить, что в результате некорректных и несвоевременных действий на первоначальном этапе расследования насильственных преступлений в ИУ, игнорирования соответствующих рекомендаций многие преступники остаются не привлеченными к уголовной ответственности, что порождает их убежденность в безнаказанности и вседозволенности поведения на территории колонии. В криминалистической литературе неоднократно освещались различные аспекты реализации частных криминалистических методик расследования преступлений, а также актуальность и востребованность проведения такого рода исследований [9]. Данный фракт, с одной стороны, приводит к совершению повторных пенитенциарных насильственных преступлений, а с другой - подрывает доверие осужденных к правоохранительным органам, поскольку у осужденных возрастает чувство незащищенности от насильственных преступных посягательств.

\section{СПИСОК ИСПОЛЬЗОВАННОЙ ЛИТЕРАТУРЫ}

1. Рогова Е. В. Учение о дифференциации уголовной ответственности / Е. В. Рогова. - М. : Юрлитинформ, 2014. - 344 c. 
2. Головин А. Ю. Криминалистические системы и классификации: вопросы практического использования / А. Ю. Головин // Известия Тульского государственного университета. Экономические и юридические науки. - 2013. - № 1-2. - С. 5-11.

3. Варданян А. В. Теоретико-методологические проблемы криминалистической тактики в контексте современной модели уголовного процесса / А. В. Варданян, Г. А. Варданян / / Юристъ-Правоведъ. - 2015. № 6 (73). - C. 5-10.

4. Варданян А. В. К вопросу о принципах формирования частных криминалистических методик / А. В. Варданян, Р. В. Кулешов / / Российский следователь. - 2015. - № 22. - С. 7-13.

5. Абатуров А. И. Уголовно-исполнительные особенности личности осужденного, совершившего злостное нарушение в местах лишения свободы / А. И. Абатуров / / Уголовно-исполнительная система: право, экономика, управление. - 2008. - № 1. - С. 29-33.

6. Гайдай М. К. Пенитенциарная система России: Иркутская область / М. К. Гайдай, Ю. Р. Герасимова, В. В. Синиченко. - Иркутск : Оператив. тип. «На Чехова», 2014. - 135 с.

7. Ишигеев В. С. Пенитенциарные преступления: характеристика, предупреждение, ответственность / В. С. Ишигеев. - Иркутск, 2004. - 67 с.

8. Костюк М. Ф. Насилие в местах лишения свободы (социально-правовой аспект) / М. Ф. Костюк // Законность. - 1998. - № 12. - С. 43-46.

9. Варданян А. В. Криминалистические классификации преступлений и их системообразующая роль в фрормировании частных криминалистических методик расследования преступлений как научно обоснованных комплексов криминалистических рекомендаций / А. В. Варданян, Р. В. Кулешов // Российский следователь. 2015. - № 21. - C. 5-10.

\section{REFERENCES}

1. Rogova E. V. Uchenie o differentsiatsii ugolovnoi otvetstvennosti [The Doctrine of Differentiation of Criminal Liability]. Moscow, Yurlitinform Publ., 2014. 344 p.

2. Golovin A. Y. Systems and Classifications in Criminalistics: Questions Used in Practice. Izvestiya Tul'skogo gosudarstvennogo universiteta. Ekonomicheskie $i$ yuridicheskie nauki = Proceedings of the Tula State University. Economics and Law, 2013, no. 1-2, pp. 3-12. (In Russian).

3. Vardanyan A. V., Vardanyan G. A. Theoretical and methodological problems of criminalistics tactics in the context of a modern model of the criminal process. Yurist"-Pravoved" = Jurist-Pravoved, 2015, no. 6 (73), pp. 5-10. (In Russian).

4. Vardanyan A. V., Kuleshov R. V. Revisiting principles of formation of individual criminalistics methods. Rossiiskii sledovatel' = Russian Investigator, 2015, no. 22, pp. 7-13. (In Russian).

5. Abaturov A. I. Criminal and Correctional Characteristics of the Personality of a Convict Who Commit a Gross Violation in a Place of Detention Ugolovno-ispolnitel'naya sistema: pravo, ekonomika, upravlenie = Criminal-Executory System: law, economy, management, 2008, no. 1, p. 29-33. (In Russian).

6. Gaidai M. K., Gerasimova Yu. R., Sinichenko V. V. Penitentsiarnaya sistema Rossii: Irkutskaya oblast' [Penitentiary System in Russia: Irkutsk Oblast]. Irkutsk, Operativnaya tipografiya «Na Chekhova» Publ., 2014.135 p.

7. Ishigeev V. S. Penitentsiarnye prestupleniya: kharakteristika, preduprezhdenie, otvetstvennost' [Penitentiary Crimes: Characteristics, Prevention, Liability]. Irkutsk, 2004. 67 p.

8. Kostyuk M. F. Violence in Places of Detention (Social and Legal Aspect). Zakonnost' = Legality, 1998, no. 12, p. 43-46. (In Russian).

9. Vardanyan A. V., Kuleshov R. V. Criminalistic classifications of crimes and their backbone role in formation of private criminalistic techniques of crime investigation as scientifically-grounded sets of criminalistic recommendations. Rossiiskii sledovatel' = Russian Investigator, 2015, no. 21, pp. 5-10. (In Russian).

\begin{abstract}
Информация об авторах
Ишигеев Владимир Степанович - доктор юридических наук, профессор, кафедра уголовного права, криминологии и уголовного процесса, Байкальский государственный университет, 664003, г. Иркутск, ул. Ленина, 11.

Грибунов ОлегПавлович - доктор юридических наук, доцент, начальник кафедры криминалистики, Восточно-Сибирский институт Министерства внутренних дел Российской Федерации, 664074, г. Иркутск, ул. Лермонтова, 110, e-mail: gribunov@mail.ru.
\end{abstract}

\section{Для цитирования}

Ишигеев В. С. Проблемы первоначального этапа расследования насильственных пенитенциарных преступлений / В.С.Ишигеев, О.П. Грибунов // Известия Байкальского государственного университета. - 2017. - T. 27, № 4. - C. 541-545. - DOI: $10.17150 / 2500-2759.2017 .27(4) .541-545$.

\section{Authors}

Vladimir S. Ishigeev - Doctor of Juridical Science, Professor, Department of Criminal Law and Criminology, Baikal State University, 11 Lenin St., 664003, Irkutsk, Russian Federation.

Oleg P. Gribunov - Doctor of Juridical Science, Associate Professor, Head of the Department of Criminalistics, East-Siberian Institute of the Ministry of the Interior of Russia, 110 Lermontov St., 664074, Irkutsk, Russian Federation, e-mail: gribunov@mail.ru.

\section{For citation}

Ishigeev V. S., Gribunov O. P. Problems of the Initial Stage of Investigation of Violent Penitentiary Crimes. Izvestiya Baykal'skogo gosudarstvennogo universiteta = Bulletin of Baikal State University, 2017, vol. 27, no. 4, pp. 541-545. DOI: 10.17150/25002759.2017.27(4).541-545. (In Russian). 